\title{
Criminal offending and the family environment: Swedish national high-risk home-reared and adopted-away co-sibling control study
}

Kenneth S. Kendler, Nancy A. Morris, Henrik Ohlsson, Sara Larsson Lönn, Jan Sundquist and Kristina Sundquist

\section{Background}

Criminal offending is strongly transmitted across generations.

\section{Aims}

To clarify the contribution of rearing environment to crossgenerational transmission of crime.

\section{Method}

Using Swedish national registries, we identified 1176 fullsibling and 3085 half-sibling sets from high-risk families where at least one sibling was adopted and the other raised by the biological parents.

\section{Results}

Risk for criminal conviction was substantially lower in the fulland half-siblings who were adopted $v$. home-reared (hazard ratios $(\mathrm{HR})=0.56,95 \% \mathrm{Cl} 0.50-0.64$ and $0.60,95 \% \mathrm{Cl} 0.56-$ 0.65 , respectively). The protective effect of adoption was significantly stronger in sibships with two $v$. one high-risk parent.

\section{Conclusions}

Using matched high-risk full- and half-siblings, we found replicated evidence that (a) rearing environment has a strong impact on risk for criminal conviction, (b) high-quality rearing environments have especially strong effects in those at high familial risk for criminal offending and (c) the protective effects of adoption are stronger for more severe crimes and for repeated offending.

\section{Declaration of interest}

None.

\section{Copyright and usage}

(C) The Royal College of Psychiatrists 2016.
Because antisocial and criminal behaviour strongly aggregate within families, ${ }^{1-4}$ an important focus of criminological research has been to understand the nature of these familial influences and to disentangle the effects of genetic and environmental factors. One prominent way to evaluate genetic and environmental effects on criminal offending has been through twin studies, which have shown that both genetic and environmental factors contribute to the familial aggregation of antisocial and criminal behaviour with genetic factors playing a somewhat stronger role. ${ }^{5}$ However, twin studies only examine within-generation familial resemblance. It is equally important to understand the sources of crossgenerational transmission of criminal behaviour. Prior studies using both officially recorded criminal justice data and self-report data have consistently shown that children of parents with a history of criminal offending have an elevated probability of being arrested or convicted of a crime and reporting high levels of antisocial and criminal behaviours. ${ }^{2,3,6-10}$ Using data from the Cambridge Study in Delinquent Development on fathers and sons, Farrington and colleagues, ${ }^{3,11,12}$ noted that rates of conviction in offspring were higher when fathers or mothers themselves were convicted of crimes. Farrington et al also reported that having a convicted parent by age 10 was among the strongest predictors of criminal offending among the males up until age 32. A range of genetic and environmental processes can lead to cross-generational continuity in criminal offending, such as socioeconomic risk factors, maternal stress, maternal parenting styles and exposure to parental criminal offending. ${ }^{13-16}$ In a study based on a sample from the Netherlands, Bijleveld \& Wijkman ${ }^{14}$ used criminal conviction data for five generations and examined the extent to which intergenerational transmission was the result of environmental or genetic influences. They found that parental conviction before birth had no impact on risk for offspring conviction; however, parental conviction after birth significantly increased the risk of offspring conviction. They conclude that their results suggest that environmental exposure to a convicted parent may be more influential for cross-generational transmission than the hereditary effects.

Although these studies have been useful for assessing the degree of familial aggregation across generations, they were unable to address directly the degree to which this results from genetic $v$. environmental influences. The primary reason for this is that these studies were performed in intact families sharing both their genes and their environment, making it difficult to disentangle their effects. One approach that is useful for discriminating genetic from environmental sources of parent-offspring resemblance has been the adoption study. Unfortunately, adoption studies have provided mixed results regarding genetic and environmental influences of familial similarity in criminal offending. ${ }^{17-22}$ We recently completed a large adoption study of criminal offending to date covering all adoptions in Sweden and found that criminal convictions in adoptees was significantly predicted by criminal conviction in both the biological and adoptive relatives, as well as other features of the adoptive home including adoptive parental alcohol or drug abuse, divorce or death. ${ }^{23}$ This paper seeks to clarify further the role of the rearing environment in the risk of criminal conviction among those individuals with high familial risk. We take advantage of a natural experiment in which different offspring of the same high-risk parents are raised by their biological parents $v$. by an adoptive family. We define high-risk parents as having a criminal conviction, alcohol use disorders (AUD) and/or drug misuse. Prior work has strongly suggested that parents with any of one of these risk factors tend to have children that are themselves at higher risk. Additionally, results from our prior adoption study ${ }^{23}$ found that the presence of any one of these disorders in biological parents significantly increased risk for a criminal conviction in their adopted-away offspring. In this paper, 
we first examined full-siblings who were offspring of a high-risk parent in which at least one sibling was raised by the natural parents and one by adoptive parents. We then attempted to replicate our findings in a parallel and independent sample of half-siblings. Gene-environment interaction has been a topic of much recent interest in human genetics, especially with regard to antisocial and criminal behaviours. ${ }^{24}$ Because of this interest and the results in one prior adoption study - where the genetic risk for criminal offending interacted statistically with the quality of the postnatal home environment provided by the adoptive family to predict criminal conviction in the adoptees ${ }^{19}$ - we examined evidence for gene $\times$ environmental interaction in these analyses. Would the differences in risk for a history of criminal offending in the home-reared $v$. adopted-away offspring be greater in those with very high $v$. moderately high genetic risk? Finally, if we find the expected reduction in risk for criminal offending in the adopted siblings, we attempt to further delineate the source of that reduced risk. In particular, how much of this effect could result from the presence of a high-risk parent in the home environment and the absence of such a parent in the adoptive family, or from difference in the community peer group of the siblings home-reared $v$. adopted-away?

\section{Method}

We used linked data from multiple Swedish nationwide registries and healthcare data using the unique individual Swedish 10-digit personal ID number assigned at birth or immigration to all Swedish residents. This ID number was replaced by a serial number to preserve confidentiality. The following sources were used to create our database: the Total Population Register, containing annual data on family and geographical status; the Multi-Generation Register, providing information on family relations; the Swedish Hospital Discharge Register, containing all admissions to hospital (mental and drug abuse) for all Swedish inhabitants from 1963 to 2010; the Swedish Prescribed Drug Register, containing all prescriptions in Sweden picked up by patients from 2005 to 2010; the Outpatient Care Register, containing information from all out-patient clinics from 2001 to 2010; the Primary Health Care Register, containing out-patient primary care data on diagnoses and time for diagnoses from 2001 to 2007 for 1 million patients from Stockholm and middle Sweden; the Swedish Crime Register that included national complete data on all convictions from 1973 to 2011; the Swedish Suspicion Register that included national complete data on all individuals strongly suspected of crime from 1998 to 2011; the Swedish Mortality Register, containing causes of death; and the Population and Housing Censuses that provided information on household and geographical status in 1960, 1965, 1970, 1975, 1980 and 1985. Geographical status was defined as small areas for market statistics (SAMS) that are small geographical units defined by Statistics Sweden (www.scb.se/en_/), the Swedish government-owned statistics bureau. There are approximately 9200 SAMS throughout Sweden, their average population being around 1000. We secured ethical approval for this study from the Regional Ethical Review Board of Lund University (No. 2008/409).

Criminal conviction data were taken from the Swedish Crime register, which includes all convictions in lower court from 1973 to 2011 but excluded convictions for minor crimes such as traffic infractions. We measured criminal conviction and two subtypes using the following criminal conviction types during the entire follow-up period: (a) violent criminal conviction - (aggravated) assault, illegal threats, intimidation and illegal coercion, threats or violence against a police officer, (aggravated) robbery, murder, manslaughter or filicide, kidnapping, arson, sexual crimes (excluding prostitution and the buying of sexual services but including child pornography); and (b) non-violent criminal conviction - fraud, forgery and dishonesty and embezzlement, theft, vandalism, vandalism causing danger to the public and trespassing. Criminal conviction is measured using all available criminal conviction types. Peer criminal offending was also measured using criminal conviction data. Our measure of peer criminal offending was created using geographical areas - SAMS - defined by Statistics Sweden to identify peers living in the same SAMS area when the proband was age 15 . We then identified the proportion of peers whose ages were within 11 years of the proband's age that went on to have a criminal conviction. Thus, for a proband born in 1970 and who is 15 at 1985, we measured the proportion of individuals born between 1965 and 1975 residing in the same SAMS that were subsequently registered for criminal conviction.

\section{Participants}

The full- and half-sibling databases were created by entering all full- and half-sibling sets born between 1955 and 1990 for which at least one of the siblings within the family was adopted prior to age 5. Siblings adopted by biological relatives or by an adoptive parent living with a biological parent were excluded. Age at formal adoption was not available in national records until 1991. We therefore estimated age at first cohabitation with adoptive parents from census data available every fifth year. This estimate represents an upper limit of the true age at adoption because other sources indicate that during this time period, since private adoptions were prohibited by Swedish law, children were taken into institutional care by the municipalities shortly after birth and adopted at a median age of 6 months with very few children adopted after 12 months of age. ${ }^{25,26}$ Furthermore, we required that at least one of the parents be high-risk defined as being registered for drug abuse, criminal conviction or AUD.

Drug abuse was identified in the Swedish medical registries by ICD codes (ICD-8: drug dependence (304); ICD-9: drug psychoses (292) and drug dependence (304); ICD-10: mental and behavioural disorders due to psychoactive substance use (F10-F19), except those as a result of alcohol (F10) or tobacco (F17)); $;^{27-29}$ in the Suspicion Register by codes 3070, 5010, 5011 and 5012, that reflect crimes related to drug abuse; and in the Crime Register by references to laws covering narcotics (law 1968:64, paragraph 1, point 6) and drug-related driving offences (law 1951:649, paragraph 4, subsection 2 and paragraph 4A, subsection 2). Drug abuse was identified in individuals (excluding those with cancer) in the Prescribed Drug Register who had received (on average) more than four defined daily doses a day for 12 months either of hypnotics and sedatives (anatomical therapeutic chemical (ATC) Classification System N05C and N05BA) or opioids (ATC: N02A).

AUD were defined by ICD codes for main and secondary diagnoses from Swedish medical registries for the following diagnoses: ICD-9: alcohol-related psychiatric disorders (291), alcohol dependence (303), alcohol abuse (305A), alcohol-related polyneuropathy (357F), alcohol-related cardiomyopathy (425F), alcohol-related gastritis (535D), alcoholic fatty liver, alcohol hepatitis, alcoholic cirrhosis, unspecified liver damage caused by alcohol (571A-D), toxic effects of alcohol (980), alcoholism (V79B); ICD-10: alcohol-related psychiatric and behavioural disorders (F10, excluding acute alcohol intoxication: F10.0), rehabilitation of a person with alcohol abuse (Z50.2), guidance and medical advice to a person with alcohol abuse (Z71.4), alcohol-related pseudo-Cushing syndrome (E24.4), alcohol-related degeneration 
of the nervous system and brain (G31.2), alcohol-related polyneuropathy (G62.1), alcohol-related myopathy (G72.1), alcohol-related cardiomyopathy (I42.6), alcohol-related gastritis (K29.2), liver diseases caused by alcohol (K70.0-K70.9), acute pancreatitis caused by alcohol (K85.2), chronic pancreatitis caused by alcohol (K86.0), treatment of pregnant alcoholic woman (O35.4), toxic effects of alcohol (T51.0-T51.9), and based on ATC codes in the Prescribed Drug Register: disulfiram (N07BB01), acamprosate (N07BB03) or naltrexone (N07BB04). Additionally, we identified individuals with at least two convictions of drunk driving (law 1951:649) or drunk in charge of maritime vessel (law 1994:1009) in the Crime register. We used the Cause of Death Register to obtain data on alcohol-associated death and used the same codes as above.

The full-sibling database included 2137 home-reared individuals and 1297 adopted-away individuals (into 1209 adoptive families) nested within 1161 biological parents. In 287 of these 1161 sets of parents, both parents were high-risk, whereas in 874 only one of the parents was high-risk. The corresponding figures for halfsiblings were 7932 home-reared, 3396 adopted-away and 3085 biological parents.

\section{Statistical methods}

Criminal conviction in offspring was investigated in relation to the main predictor variable, adopted $v$. not adopted, by stratified Cox proportional hazards models with a separate stratum for each sibling set. Follow-up time in number of years was measured from age 15 of the child until year of first registration for criminal conviction, death, emigration or end of follow-up (year 2011), whichever came first. In all models we investigated the proportionality assumption. The stratified Cox proportional hazards models provides a participant-specific regression coefficient for adopted-away $v$. home-reared adjusted for the familial cluster, and therefore accounts for shared genetic factors. We present the hazard ratio (HR) and a 95\% confidence interval. In order to compare the hazard ratios from different samples we used the Mantel-Haenszel method ${ }^{30}$ and we present the $P$-values for the heterogeneity test. Statistical analyses were performed using SAS 9.3.

\section{Results}

\section{Full-siblings}

We identified 1176 full-sibling sets where one or both biological parents were high risk and at least one sibling within each set was adopted-away. The ages of the parents at the birth of the home-reared (mean 26.4, s.d. $=5.6$ ) and adopted (mean 27.5, s.d. $=6.1$ ) siblings were similar. The raw rates for a lifetime history of criminal conviction were $41.0 \%$ in the home-reared and $26.6 \%$ in the adopted siblings. As seen in Table 1, the raw HR for criminal conviction in an adopted $v$. home-reared sibling was 0.57 (95\% CI $0.51-0.64)$ and was not attenuated by controlling for parental age at birth and gender.

Among the full-sibling sets, 287 had two high-risk biological parents. We therefore examined whether the difference in risk for criminal conviction in the adopted $v$. home-reared members of these sibships varied based on a function of the number of high-risk biological parents. The raw HR for criminal conviction in the adopted $v$. home-reared full-siblings was 0.63 (95\% CI 0.56-0.72) in sibships with one high-risk biological parent and 0.43 (95\% CI 0.35-0.54) among pairs with two high-risk biological parents. The heterogeneity test was significant $(P=0.001)$.

We next examined among these full-sibships whether actually residing in the same house with a high-risk biological or adoptive parent modified the effects of adoption on risk for criminal conviction. Indeed, the protective effect of adoption was significantly stronger when the home-reared sibling resided with $(\mathrm{HR}=0.43,95 \%$ CI $0.35-0.53) v$. did not reside with their highrisk parent $(\mathrm{HR}=0.66,95 \% \mathrm{CI} 0.58-0.75)$ (heterogeneity test $P=0.0007)$. Furthermore, the protective effect of adoption was significantly weaker when one ( $\mathrm{HR}=0.90,95 \%$ CI $0.66-1.22) v$. none of the adoptive parents were high-risk $(\mathrm{HR}=0.53,95 \% \mathrm{CI}$ $0.47-0.60$ ) (heterogeneity test $P=0.002$ ).

Finally, we sought to determine how much the protective effect of adoption on criminal conviction might result from community-level influences. We have previously shown that rates of future drug abuse and criminal conviction in similar-aged peers within SAMS areas in Sweden robustly predict future risk for drug abuse and criminal conviction (Kendler et $a l^{31}$ and further details available from the authors on request). We then added as a covariate to our main analysis the level of future criminal conviction in the peers of all the members of the full- sibling sets. For full-siblings, the protective effect of adoption was slightly reduced from $\mathrm{HR}=0.57(95 \% \mathrm{CI} 0.51-0.64)$ to $\mathrm{HR}=0.62(95 \%$ CI $0.52-0.73$ ).

\section{Half-siblings}

We identified 3085 half-sibling sets all members of whom had at least one high-risk biological parent and where at least one sibling was home-reared and one adopted-away. In these sets, parents were on average somewhat younger at the birth of the adopted sibling (mean 25.3, s.d. $=5.9$ ) than at the birth of the home-reared sibling (mean 28.4, s.d. =6.9). The raw rates for criminal conviction were $35.9 \%$ in the home-reared and $26.9 \%$ in the adopted sibling. As seen in Table 1, the hazard ratio for conviction for being an

\begin{tabular}{|c|c|c|c|}
\hline & \multicolumn{3}{|c|}{ Hazard ratio $(95 \% \mathrm{Cl})$} \\
\hline & Raw & $\begin{array}{l}\text { Controlling for non-shared } \\
\text { parent in half-siblings }\end{array}$ & $\begin{array}{l}\text { Controlling for parental } \\
\text { age and gender }\end{array}$ \\
\hline \multicolumn{4}{|l|}{ Full-siblings ( $n=1176$ sets) } \\
\hline Adopted v. not adopted & $0.57(0.51-0.64)$ & - & $0.56(0.50-0.64)$ \\
\hline Parental age at birth & - & - & $0.98(0.96-1.00)$ \\
\hline Male gender & - & - & $3.46(2.99-3.99)$ \\
\hline \multicolumn{4}{|l|}{ Half-siblings ( $n=3085$ sets) } \\
\hline Adopted v. not adopted & $0.66(0.61-0.70)$ & $0.65(0.61-0.70)$ & $0.60(0.56-0.65)$ \\
\hline Parental age at birth & - & - & $0.98(0.98-0.99)$ \\
\hline Male gender & - & - & $3.18(2.95-3.43)$ \\
\hline High-risk status in non-shared parent & - & $1.36(1.25-1.49)$ & $1.47(1.34-1.61)$ \\
\hline
\end{tabular}


adopted $v$. home-reared half-sibling was 0.66 (95\% CI 0.61-0.70), which became somewhat stronger when controlling for parental age at birth, gender and the high-risk status of the non-shared parent: 0.60 (95\% CI 0.56-0.65).

We divided our half-sibship sample (all of whom had one high-risk biological parent) into three groups: (a) those where all the half-siblings had two high-risk biological parents $(n=383)$, those where some of the half-siblings had two high-risk biological parents $(n=1397)$ and those where none of the halfsiblings had two high-risk biological parents $(n=1305)$. The protective effect of adoption was strongest in the half-sibships where all members had two high-risk biological parents $(\mathrm{HR}=0.42,95 \%$ CI $0.35-0.52)$, intermediate in those where the parents of some of the members were both high-risk $(\mathrm{HR}=0.63,95 \%$ CI $0.57-0.69)$ and weakest in those sibships where none of the members had two high-risk biological parents $(\mathrm{HR}=0.81,95 \% \mathrm{CI} 0.73-0.91)$. These three hazard ratios differed significantly from one another $(P<0.0001)$.

We then examined in these half-sibships whether residing with a high-risk biological or adoptive parent modified the protective effects of adoption. The effect of adoption on risk for conviction did not differ when the home-reared half-siblings resided with $(\mathrm{HR}=0.64,95 \%$ CI 0.59-0.70) $v$. did not reside with a high-risk parent $\quad(\mathrm{HR}=0.69, \quad 95 \% \quad \mathrm{CI} \quad 0.61-0.78) \quad$ (heterogeneity test $P=0.34)$. However, the protective effect of adoption was significantly weaker in the half-sibships when one $(\mathrm{HR}=0.84,95 \% \mathrm{CI} 0.70-1.02)$ $v$. none of the adoptive parents were high-risk $(\mathrm{HR}=0.64,95 \% \mathrm{CI}$ $0.59-0.68$ ) (heterogeneity test $P=0.007$ ).

Finally, the protective effect of adoption in the half-sibling sets did not appreciably change when adding, as a covariate, the level of future criminal conviction in peers: from $\mathrm{HR}=0.66(95 \% \mathrm{CI}$ 0.61-0.70) to $\mathrm{HR}=0.67$ (95\% CI 0.61-0.73).

\section{Impact of adoption on different types and severity of convictions}

Our prior analyses focused entirely on the effect of adoption on risk for any lifetime criminal conviction. Here, we examine whether the impact of adoption varies by the type of conviction, first by broad class and then by individual type. In the full-sibling sets, the protective effects of adoption were non-significantly stronger for violent $(\mathrm{HR}=0.46,95 \%$ CI $0.38-0.55)$ than for non-violent lifetime conviction $(\mathrm{HR}=0.54,95 \% \mathrm{CI} 0.48-0.61)$ (heterogeneity test $P=0.145$ ). The results in the half-sibling sets were similar for violent $(\mathrm{HR}=0.57,95 \%$ CI $0.52-0.64)$ and nonviolent convictions ( $\mathrm{HR}=0.65,95 \% \mathrm{CI} 0.60-0.70)$ (heterogeneity test $P=0.061$ ).

The protective effects of adoption on individual categories of criminal convictions in both the full- and half-sibling sets is seen in Fig. 1, which depicts the hazard ratio for adoption for select crime conviction types from the most common (theft) to the rarest (homicide). Overall, there are few striking trends. The protective effect of adoption is somewhat weaker for sexual-based crimes convictions and in half-sibling sets only for arson. A modest trend is seen, consistent with the above analyses, for the effects of adoption to be stronger for the more severe or violent crimes. For example, it is stronger in both sibling groups for robbery than for theft and particularly strong for homicide.

Finally, we explored whether the adoption effect would vary as a function of criminal severity measured by the number of lifetime convictions. We examined three groups of offenders: those with (a) one lifetime conviction, (b) two to four convictions and (c) $\geqslant 5$ lifetime convictions. In the full-sibling sets, the protective effects of adoption were increasingly strong with higher levels of recidivism: one conviction $\mathrm{HR}=0.69$ (95\% CI 0.57-0.84); two to four convictions $\mathrm{HR}=0.50$ (95\% CI $0.39-0.63$ ); and $\geqslant 5$ lifetime convictions $\mathrm{HR}=0.40$ (95\% CI $0.32-0.49)$ (heterogeneity test $P=0.0006)$. A similar pattern was seen in the half-sibling sets: one conviction $\mathrm{HR}=0.72$ (95\% CI $0.64-0.81$ ); two to four convictions $\mathrm{HR}=0.66$ (95\% CI $0.58-0.74)$; and $\geqslant 5$ lifetime convictions $\mathrm{HR}=0.56$ (95\% CI $0.50-0.63)$ (heterogeneity test $P=0.01$ )

\section{Discussion}

\section{Main findings}

We sought to elucidate the role of the rearing environment in risk for a criminal conviction by utilising a natural experiment wherein offspring of a high-risk biological parent were reared in home $v$. adoptive environments. In full-sibling sets, being raised by an adoptive family was associated with a $44 \%$ decreased risk for

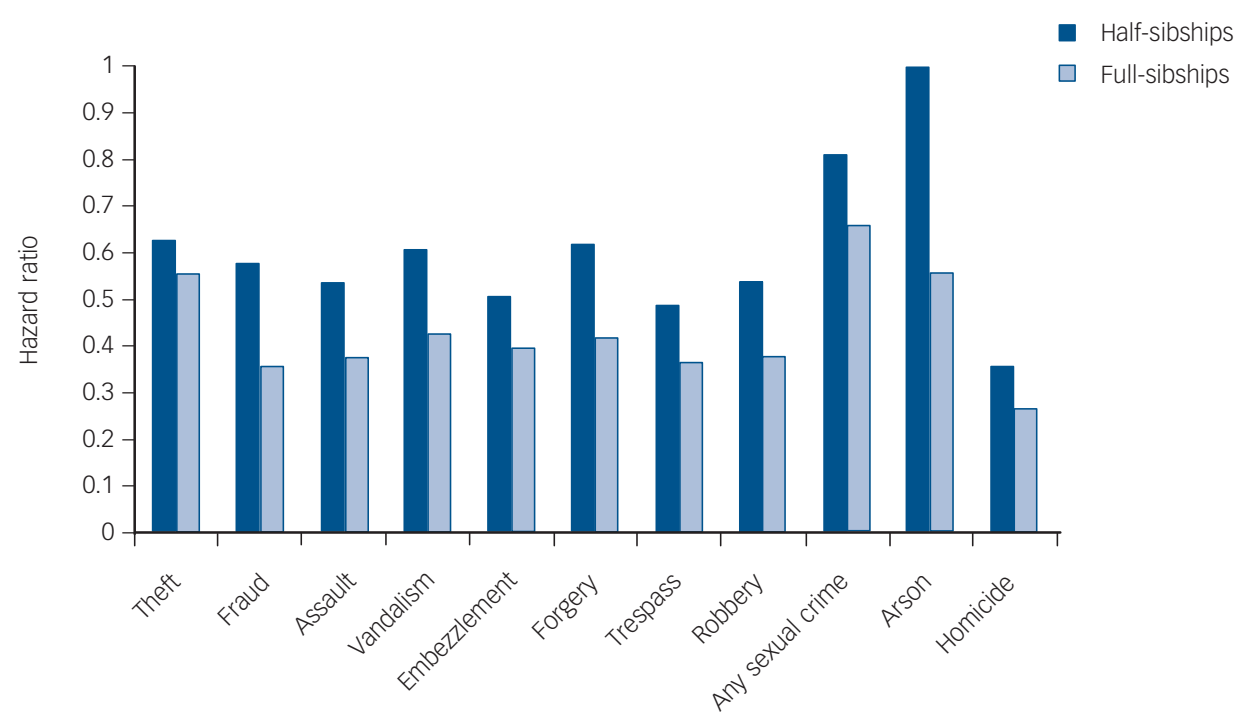

Fig. 1 The hazard ratio for major categories of criminal offending in adopted-away $v$. home-reared full- and half-sibling pairs as provided by the Swedish Conviction Registry.

These categories are listed from the most common (to the left) to the rarest (on the right). 
criminal conviction. In an independent sample of sets of high-risk half-siblings, we replicated these findings. Controlling for the high-risk status in the parent not shared by the half-siblings, the adopted half-sibling had a $40 \%$ decrease in risk for criminal conviction compared with his or her home-reared half-sibling.

We then divided our sibling sets on the basis of whether one or both parents were high-risk. In our full-sibling sets, the reduction in risk for criminal conviction associated with adoption was significantly stronger in the offspring of two high-risk parents than in the offspring of one high-risk parent. We found essentially the same results in our half-sibling pairs. The benefits of being reared in an adoptive home $v$. home-reared appear to be greatest in those offspring at highest familial risk for criminal behaviour.

We next sought to gain insight into some of the factors that contribute to the reduction in risk for criminal conviction from being reared in an adoptive home. In the full-siblings, we found that the protective effects of adoption on rates of criminal conviction were appreciably increased when a high-risk biological parent was residing in the home environment and decreased when an adoptive parent was high risk. These results are consistent with prior studies $^{3,32,33}$ and our own adoption results ${ }^{23}$ that suggest that highrisk parents can - via several potential environmental mechanisms - increase risk for criminal offending in their offspring.

Finally, we examined how much the protective effect of adoption would be reduced by controlling for the future risk for criminal conviction in the near-age peers in the home-reared and adopted sibling and half-sibling sets. The change was quite modest, suggesting that relatively little of the protective effect of adoption on risk for criminal offending was a result of changes in residing next to a similarly aged peer group with high risk for future criminal convictions.

\section{Interpretation}

The only human trait of which we are aware that has been examined utilising the design we implement here has been IQ. Several prior investigations have shown substantial gains in IQ or improvements in school performance in adopted $v$. nonadopted siblings. ${ }^{34-37}$ The rearing environment provided by an adoptive family might reduce risk for convictions in many ways. Adoptive parents are carefully screened in Sweden for their ability to provide a high-quality rearing environment. ${ }^{25}$ Because the number of children available for adoption has been considerably smaller than the demand, the selection process is rigorous. Bohman notes that this process in Sweden was designed to 'assess the general health, personality, and mutual relationship of the presumptive adoptive parents' with the goal of forecasting 'the durability of their marriage ... [and] place the child in an harmonious, stable environment . . .25

Many aspects of parental and family functioning assessed in intact families correlate with risk for offspring criminal behaviour including low socioeconomic status, young parental age, parental divorce or death, a parental history of criminal behaviour and/or psychopathology, and disrupted family functioning (for example Giordano, ${ }^{33}$ Lilly et $a l^{38}$ Farrington et $a l^{39}$ ). We have shown that compared with the biological parents of adoptees, adoptive parents in Sweden have substantially lower rates of many of these risk factors including a history of criminal conviction, drug abuse, psychiatric hospital admission, AUD and divorce, and had higher rates of education and were on average substantially older. $^{23,40}$ Many of these features in the adoptive parents (including criminal convictions, AUD, drug abuse, divorce and young age) significantly predicted risk for criminal conviction in their adopted child so that we can be sure that their effect was environmentally mediated.$^{23}$

\section{Limitations}

These results should be interpreted in the context of five potentially important methodological limitations. First, these results apply only to Swedish populations at high risk for externalising traits or disorders and it is an empirical question as to whether they would generalise to other populations. Second, full-siblings share, on average, only $50 \%$ of their genes identical by descent. Thus, at the level of the individual sibling pair, our design only partially controls for level of genetic risk. This level of control is even lower in half-siblings who share, on average, $25 \%$ of their genes. However, given our large sample sizes, in the absence of any systematic bias, we would expect level of genetic risk to be well matched across the full- and half-sibs who are raised in their home environment $v$. adopted-away. We have no information to address possible biases in the parental decision to adopt. But this decision typically occurred in infancy and the more likely propensity - to adopt away more difficult infants - would bias downward rather than upward any protective effect of adoption on risk for crime. ${ }^{41}$

Third, our measure of criminal offending is based solely on criminal convictions. Only a modest proportion of all crimes result in arrests and convictions. ${ }^{39}$ Although the use of nationwide criminal conviction data allows for the collection of longitudinal data across families more easily than self-reported data on criminal offending, there are a number of limitations associated with strictly using official conviction data, such as failure to include undetected, unreported crimes and crimes that do not result in a conviction. Additionally, using conviction data as a measure for criminal behaviour across generations could lead to biases if the probability that a committed crime is reported, recorded or leads to a conviction differs across families. This latter issue is especially problematic if children of convicted parents are more likely to experience criminal justice system processing bias resulting in an increased probability of detection and conviction.

Fourth, perhaps the observed protective effect of adoption on risk for criminal conviction arises largely because adoptive parents in Sweden have, on average, considerably more socioeconomic resources (education, income) compared with biological parents of adoptees. ${ }^{23}$ This may result in a lower probability that the criminal behaviour of the adoptees will be detected, pursued and ultimately result in conviction. However, if our findings arose from biases in police or judicial practices resulting from the higher socioeconomic status of adoptees $v$. their home-reared siblings, we would expect that the protective effect of adoption would be more pronounced for crimes that less frequently result in conviction and for individuals with few lifetime convictions. However, our results are not consistent with this pattern. The protective effect of adoption is stronger for violent than for non-violent crime and for individuals with higher $v$. lower levels of recidivism. When examined within individual crime categories, the protective effect of adoption is low for some crimes for which individuals are infrequently convicted such as sexual crimes and vandalism, and high for some crimes where we would expect very high rates of conviction such as murder. These results argue against the hypothesis that a substantial proportion of the observed protective effect of adoption on criminal conviction is artifactual and the result of police and judicial factors rather than a true lowering of rates of criminal offending.

Fifth, the gravest threat to the validity of the standard adoption design is assortative placement where characteristics of the biological and adoptive family that are relevant to the trait being studied in the adoptee are correlated. However, the homereared and adopted-away co-sibling control design would be much less sensitive to such a bias as selective placement would not likely have an impact on the key instrumental variable in this design the differences in rearing experiences of the matched siblings. 
Furthermore, in our prior adoption study of criminal conviction in Sweden, we assessed assortative placement for aggregate risk estimates for the biological and adoptive families and it was very modest $(+0.12) .^{23}$

Kenneth S. Kendler, MD, Virginia Institute for Psychiatric and Behavioral Genetics, Department of Psychiatry and Department of Human and Molecular Genetics, Virginia commonwealth University, Richmond, Virginia, USA; Nancy A. Morris, PhD, Department of Criminal Justice, Virginia Commonwealth University, Richmond, Virginia, USA; Henrik Ohlsson, PhD, Sara Larsson Lönn, PhD, Center for Primary Health Care Research, Lund University, Malmö, Sweden; Jan Sundquist, MD, PhD Kristina Sundquist, MD, PhD, Center for Primary Health Care Research, Lund Kristina Sundquist, MD, PhD, Center for Primary Health Care Research, Lund
University, Malmö, Sweden and Stanford Prevention Research Center, Stanford University School of Medicine, Stanford, California, USA

Correspondence: Kenneth S. Kendler, MD, Virginia Institute for Psychiatric and Behavioral Genetics of VCU, Box 980126, Richmond, VA 23298-0126, USA. Email: kenneth.kendler@vcuhealth.org

First received 29 Oct 2014, final revision 15 Dec 2015, accepted 26 Jan 2016

\section{Funding}

This project was supported by the Ellison Medical Foundation, the Swedish Research Council to K.S. (K2012-70X-15428-08-3), the Swedish Research Council for Health, Working Life and Welfare (in Swedish: Forte; Reg.nr: 2013-1836) to K.S., the Swedish Research Council to J.S. (2012-2378) as well as ALF funding from Region Skåne awarded to J.S. and K.S.

\section{References}

1 Burt SC. The Young Delinquent. University of London Press, 1925.

2 Glueck S, Glueck ET. Unraveling Juvenile Delinquency (1st edn). Harvard University Press, 1950.

3 Farrington DP, Gundry G, West DJ. The familial transmission of criminality. Med Sci Law 1975; 15: 177-86.

4 Farrington DP, Jolliffe D, Loeber R, Stouthamer-Loeber M, Kalb LM. The concentration of offenders in families, and family criminality in the prediction of boys' delinquency. J Adolesc 2001; 24: 579-96.

5 Rhee SH, Waldman ID. Genetic and environmental influences on antisocial behavior: a meta-analysis of twin and adoption studies. Psychol Bull 2002; 128: $490-529$.

6 McCord J. A comparative study of two generations of Native Americans. In Theory in Criminology: Contemporary Views (ed RF Meier): 83-92. Sage Publications, 1977

7 Rowe DC, Farrington DP. The familial transmission of criminal convictions. Criminology 1997; 35: 177-202.

8 Farrington DP, Coid JW, Murray J. Family factors in the intergenerational transmission of offending. Crim Behav Ment Health 2009; 19: 109-24.

9 Thornberry TP. The apple doesn't fall far from the tree (or does it?): intergenerational patterns of antisocial behavior - the American Society of Criminology 2008 Sutherland address. Criminology 2009; 47: 297-325.

10 Besemer S. Specialized versus versatile intergenerational transmission of violence: a new approach to studying intergenerational transmission from violent versus non-violent fathers: latent class analysis. J Quant Criminol 2012; 28: 245-63.

11 Farrington DP, Coid JW, Harnett LM, Jolliffe D, Soteriou N, Turner RE, et al. Criminal Careers up to Age 50 and Life Success up to Age 48: New Findings from the Cambridge Study in Delinquent Development. Home Office Research Study 299 (2nd edn). Development and Statistics Directorate, 2006

12 Bijleveld CC, Farrington DP. The importance of studies of intergenerational transmission of antisocial behaviour. Crim Behav Ment Health 2009; 19: 77-9.

13 Thornberry TP, Freeman-Gallant A, Lovegrove PJ. Intergenerational linkages in antisocial behaviour. Crim Behav Ment Health 2009; 19: 80-93.

14 Bijleveld CC, Wijkman M. Intergenerational continuity in convictions: a five-generation study. Crim Behav Ment Health 2009; 19: 142-55.

15 Delisi M, Beaver KM, Vaughn MG, Wright JP. All in the family. Gene $\times$ environment interaction between DRD2 and criminal father is associated with five antisocial phenotypes. Crim Justice Behav 2009; 36: 1187-97.
16 Patterson GR. Coercive Family Process. Castalia Publishing Company, 1982

17 Crowe RR. The adopted offspring of women criminal offenders. A study of their arrest records. Arch Gen Psychiatry 1972; 27: 600-3.

18 Bohman M, Cloninger CR, Sigvardsson S, von Knorring AL. Predisposition to petty criminality in Swedish adoptees. I. Genetic and environmental heterogeneity. Arch Gen Psychiatry 1982; 39: 1233-41.

19 Cloninger CR, Sigvardsson S, Bohman M, von Knorring AL. Predisposition to petty criminality in Swedish adoptees. II. Cross-fostering analysis of gene-environment interaction. Arch Gen Psychiatry 1982; 39: 1242-7.

20 Mednick SA, Gabrielli WF, Jr., Hutchings B. Genetic influences in criminal convictions: evidence from an adoption cohort. Science 1984; 224: 891-4.

21 Gabrielli WF, Jr., Mednick SA. Urban environment, genetics, and crime. Criminology 1984; 22: 645-52.

22 Bohman M. Some genetic aspects of alcoholism and criminality. A population of adoptees. Arch Gen Psychiatry 1978; 35: 269-76.

23 Kendler KS, Larsson Lönn S., Morris NA, Sundquist J, Långström N, Sundquist K. A Swedish National Adoption Study of Criminality. Psychol Med 2014; 44: 1913-25.

24 Moffitt TE. The new look of behavioral genetics in developmental psychopathology: gene-environment interplay in antisocial behaviors. Psychol Bull 2005; 131: 533-54.

25 Bohman M. Adopted Children and their Families: A Follow-Up Study of Adopted Children, their Background, Environment and Adjustment. Proprius, 1970.

26 Nordlöf B. Svenska Adoptioner i Stockholm 1918-1973. [Swedish Adoptions in Stockholm 1918-1973.] FoU-rapport 2001:8. Socialtjänstförvaltningen, Forsknings-och utvecklingsenheten, 2001.

27 World Health Organization. International Statistical Classification of Diseases and Related Health Problems (ICD-8). WHO, 1967.

28 World Health Organization. International Statistical Classification of Diseases and Related Health Problems (ICD-9). WHO, 1978.

29 World Health Organization. The ICD-10 Classification of Mental and Behavioural Disorders: Clinical Descriptions and Diagnostic Guidelines. WHO, 1992.

30 Mitchell JE, Maki DD, Adson DE, Ruskin BS, Crow S. The selectivity of inclusion and exclusion criteria in bulimia nervosa treatment studies. Int J Eat Disord 1997; 22: 243-52.

31 Kendler KS, Ohlsson H, Sundquist K, Sundquist J. Peer deviance, parental divorce, and genetic risk in the prediction of drug abuse in a nationwide Swedish sample: evidence of environment-environment and geneenvironment interaction. JAMA Psychiatry 2014; 71: 439-45.

32 Farrington DP, Lambert S, West DJ. Criminal careers of two generations of family members in the Cambridge Study in Delinquent Development. Stud Crime Crime Prev 1998; 7: 85-106.

33 Giordano PC. Legacies of Crime: A Follow-Up of the Children of Highly Delinquent Girls and Boys. Cambridge University Press, 2010.

34 van Ijzendoorn $\mathrm{MH}$, Juffer $\mathrm{F}$, Poelhuis $\mathrm{CW}$. Adoption and cognitive development: a meta-analytic comparison of adopted and nonadopted children's IQ and school performance. Psychol Bull 2005; 131: 301-16.

35 Schiff M, Duyme M, Dumaret A, Stewart J, Tomkiewicz S, Feingold J. Intellectual status of working-class children adopted early into upper-middleclass families. Science 1978; 200: 1503-4.

36 Dumaret A. IQ, scholastic performance and behaviour of sibs raised in contrasting environments. J Child Psychol Psychiatry 1985; 26: 553-80.

37 Kendler KS, Turkheimer E, Ohlsson H, Sundquist J, Sundquist K. Family environment and the malleability of cognitive ability: a Swedish national home-reared and adopted-away cosibling control study. Proc Natl Acad SCi USA 2015; 112: 4612-7.

38 Lilly JR, Cullen FT, Ball RA. Criminological Theory: Context and Consequences (5th edn). Sage Publications, 2010.

39 Farrington DP, Piquero AR, Jennings WG. Offending from Childhood to Late Middle Age: Recent Results from the Cambridge Study in Delinquent Development. Springer, 2013.

40 Kendler KS, Sundquist K, Ohlsson H, Palmer K, Maes H, Winkleby MA, et al. Genetic and familial environmental influences on the risk for drug abuse: a national Swedish adoption study. Arch Gen Psychiatry 2012; 69: 690-7.

41 Caspi A, Moffitt TE, Newman DL, Silva PA. Behavioral observations at age 3 years predict adult psychiatric disorders. Longitudinal evidence from a birth cohort. Arch Gen Psychiatry 1996; 53: 1033-9. 